\title{
Non-invasive high-speed isotopic Raman spectroscopy for biomedical applications (Retraction Notice)
}

\begin{abstract}
Aleksandr Grishkanich, Aleksandr Zhevlakov, Egor Mikharev, Andrey Lunev, Boris Karas, et al.
\end{abstract}

Aleksandr Grishkanich, Aleksandr Zhevlakov, Egor Mikharev, Andrey Lunev, Boris Karas, Viktoria Pozdniakova, "Non-invasive high-speed isotopic Raman spectroscopy for biomedical applications (Retraction Notice)," Proc. SPIE 11654, High-Speed Biomedical Imaging and Spectroscopy VI, 1165419 (10 November 2021); doi: 10.1117/12.2589071 


\title{
Non-invasive high-speed isotopic Raman spectroscopy for biomedical applications (Retraction Notice)
}

\author{
Aleksandr Grishkanich, ${ }^{1,2}$ Aleksandr Zhevlakov, ${ }^{3}$ Egor Mikharev, ${ }^{4}$ Andrey Lunev, ${ }^{4}$ Boris Karas, ${ }^{5}$ Viktoria \\ Pozdniakova 5 \\ 'LLC Photonics Systems (Russian Federation) \\ 2LLC Shvabe (Russian Federation) \\ 3S. I. Vavilov State Optical Institute (Russian Federation) \\ "Saint Petersburg Electrotechnical Univ. "LETI" (Russian Federation) \\ 5ITMO Univ. (Russian Federation) \\ Proceedings Volume 11654, High-Speed Biomedical Imaging and Spectroscopy VI; 1165419 \\ (2021) https://doi.org/10.1117/12.2589071
}

Event: SPIE BIOS, 2021, Online Only

Online Publication Date: 5 March 2021

Withdrawn from Publication: 10 November 2021

Publisher's Note: This paper, originally published on March 5, 2021 was retracted from the SPIE Digital Library on November 10, 2021, by the publisher and in agreement with the authors, upon verification that a substantial portion of the paper was copied from the following work without attribution or permission: A.V. Polishchuk, "Development of a Raman gas analyzer for isotopologues of carbon-containing compounds with ultraspectral resolution," Doctoral Thesis, ITMO University, November 18, 2020. 